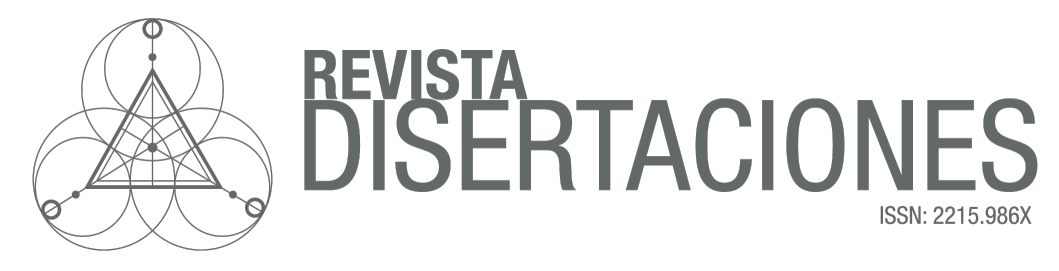

\title{
Efecto pathémico y veridicción en una crónica multimodal sobre la violencia de Estado en Colombia ${ }^{*}$
}

The Pathematic Effect and Veridiction in a Multimodal Chronicle about State

Violence in Colombia

Giomar Daniela Gómez Camacho"
Paula Karina Manrique Carvajal"

$\Phi$

\section{Resumen}

Este estudio expone la posibilidad de abordaje de un texto multimodal a partir de la integración del concepto de pathos. De ahí que busque ver la manera en la que los modos del corpus se integran para dar sostén a un efecto sensibilizador en quien lee. La metodología que se propone corresponde a la propuesta de la Gramática de la Multimodalidad y del concepto de "sinestesia" de Cope y Kalantzis. Además, se plantea un análisis aplicado de la propuesta del influjo de las emociones en la audiencia a partir de Aristóteles y Plantin. Las dos propuestas mencionadas se articulan con el problema de la construcción de la verdad en ámbitos de violencia política en Colombia, atravesados por los medios de comunicación y por la validación de múltiples juegos de veridicción sobre lo real.

Palabras clave: multimodalidad, emociones, efecto patémico, discurso.

\footnotetext{
"Recibido: 25 de agosto de 2020. Aprobado: 30 de septiembre de 2020.

${ }^{+}$Contacto: giodagomcam0730@ hotmail.com

‡Contacto: paulak_manrique@hotmail.com
} 
Giomar Daniela Gómez Camacho

Paula Karina Manrique Carvajal

\begin{abstract}
This article shows a multimodal text approach possibility based on the integration of the pathos concept. Therefore, it seeks for the ways in which the corpus' modes integrate themselves to give support to a sensitizing effect in the reader. The proposed methodology corresponds to Cope y Kalantzis' grammar of multimodality and the concept of synesthesia. Furthermore, an applied analysis, based on Aristotle and Plantin, about emotions impact in the audience, is proposed. Both mentioned proposals are articulated with the truth construction problem related to political violence fields in Colombia, which are pierced by the media and the validation of multiple veridiction games about the reality.
\end{abstract}

Keywords: multimodality, veridiction, pathematic effect, discourse.

\title{
(c) $(1) \Theta(\Theta$
}

Material publicado de acuerdo con los términos de la licencia Creative Commons AttributionNonCommercial-NoDerivatives 4.0 International (CC BY-NC-ND 4.0). Usted es libre de copiar o redistribuir el material en cualquier medio o formato, siempre y cuando dé los créditos apropiadamente, no lo haga con fines comerciales y no realice obras derivadas. 
Efecto pathémico y veridicción en una crónica multimodal sobre la violencia de Estado en Colombia

\section{Introducción}

Los discursos multimodales se caracterizan por reunir distintos recursos semióticos para generar efectos de sentido. En este artículo, analizamos esos efectos en la crónica multimodal "Dimar Torres: el crimen al que quisieron echarle tierra", del periodista José Guarnizo (2019), publicada en el portal web de la revista Semana. La elección del objeto de estudio se justifica por la conjunción de los tres modos (escrito, ilustrativo y audible) sobre la cual se construye una versión de un hecho violento como una verdad oculta que la crónica revela.

La crónica relata el asesinato de Dimar Torres, un desmovilizado de la extinta guerrilla de las FARC-EP, ahora Partido político FARC, a manos del ejército colombiano. El hecho ocurrió el 22 de abril de 2019 y tuvo una resonancia considerable en el país. Debido a la forma en la que fue tomado el hecho por la institucionalidad del gobierno de turno, el cronista se propone revelar "la historia no contada de la ejecución extrajudicial", a partir de la consideración de otras voces cercanas a la víctima, que recogen las impresiones del crimen perpetrado por miembros del Ejército Nacional y, en principio, negado por sus altos miembros. Por lo anterior, analizar la forma en que se amalgaman los modos que vertebran la crónica permite vislumbrar una arista de la problemática social del asesinato de líderes sociales en Colombia, relacionada con la construcción de la verdad pública en las esferas gubernamentales del país.

El medio por el cual se difundió el producto audiovisual corresponde al portal web de la revista Semana. Un portal con acceso libre en ese momento, en el cual se redistribuye el poder semiótico en tanto que vemos cómo Guarnizo, particularmente, y la revista, de forma general, crean y difunden significados; de esta manera, la pantalla, y el acceso a internet quiebran la hegemonía del papel, que antaño revista o periódico físico llegaba a tener un auditorio mucho más reducido.

Frente a la incidencia que, proponemos, tienen las pasiones en la generación del sentido en ese producto mediático, retomamos la visión retórica clásica de las pasiones 
Giomar Daniela Gómez Camacho

Paula Karina Manrique Carvajal

según la cual ellas "son, ciertamente, las causantes de que los hombres se hagan volubles y cambien en lo relativo a sus juicios" (Aristóteles 1994 310). Crear texto a partir de hechos o situaciones que quiebran el statu quo emocional de quien lee induce a una inclinación o conducción pasional que, en el corpus analizado, puede traducirse en compasión. Al respecto, Aristóteles menciona que el carácter compasivo se percibe "en un cierto pesar por la aparición de un mal destructivo y penoso en quien no lo merece, que también cabría esperar que lo padeciera uno mismo o alguno de nuestros allegados" (Id. 353). En este sentido, existen personas y sucesos que son dignos de compasión, dentro de las que se encuentran: "la muerte, la violencia para con el cuerpo y los malos tratos" (Id. 356).

En la misma línea de la visión clásica, Plantin (2014) vuelve al concepto de ethos y propone las reglas de producción retórica de la emoción. Sobre el ethos, el autor lo retoma como "la impresión moral producida por el orador" (41). Tal impresión implica todo el andamiaje emotivo sobre el que el orador, emisor del discurso o, en este caso particular, el cronista estructura lo que dice. Respecto a las reglas de producción retórica de la emoción, el autor recoge un conjunto de cinco directrices sobre las que se erigen los procesos de persuasión emotiva. Las reglas referidas son: 1) la representación de los objetos; 2) la representación no discursiva de objetos y acontecimientos emocionantes; 3) la descripción, amplificación y conversión de hechos emocionantes; 4) La presentación directa de la emoción, y 5) el formateo de los datos de base de la interacción. Asimismo, es preciso tener en cuenta los Principios de inferencia emocional, pues dan luces sobre la relación de las proposiciones con los disparadores lingüísticos, de forma más prolija.

En consonancia con lo anterior, es decir, con el hecho de que el texto busque la movilización de emociones a partir de su estructura multimodal, consideramos pertinente referirnos al concepto de veridicción propuesto por Foucault. Las veridicciones son

[e]ntendidas como las formas según las cuales se articulan, en un dominio de cosas, discursos susceptibles de ser llamados verdaderos o falsos: cuáles han sido las condiciones de esta emergencia, el precio que, en alguna medida, ésta ha pagado, sus efectos en lo real y 
Efecto pathémico y veridicción en una crónica multimodal sobre la violencia de Estado en Colombia

el modo en que, ligando cierto tipo de objeto a determinadas modalidades del sujeto, dicha emergencia ha constituido, para un tiempo, para un área y para individuos dados, el a priori histórico de una experiencia posible (1999 364).

La veridicción o efecto de verdad permite apuntalar la crónica como un producto que reviste credibilidad en el marco de tergiversaciones oficiales y mediáticas, en torno al asesinato de líderes sociales; contexto sociopolítico dentro del cual se inserta la crónica. Así, tienen lugar los juegos de verdad al confrontar las versiones que se tienen sobre un mismo hecho ya no como versiones, sino revelaciones de los hechos reales que han sido ocultados intencionalmente.

En lo tocante al aspecto metodológico, tomamos como fuente primaria la Gramática de la multimodalidad de Cope y Kalantzis, dado que propone, aun cuando los modos contienen en sí potencialidades disímiles de representación, una creación de representaciones análogas, a través de la integración o complementariedad de cada uno de ellos. Lo anterior se traduce en el término empleado por los autores como sinestesia, puesto que ella proyecta "el proceso de cambio entre modos y la nueva representación de la misma cosa desde un modo" (3).

En este sentido, la sinestesia propende por la confección del efecto emotivo del lector, debido a que "en un sentido material y muy ordinario, nuestras sensaciones corporales están integradas de forma holística, incluso aunque el enfoque de nuestra atención en la construcción de significado en un momento concreto pudiera ser el de un modo especifico" (Cope y Kalantazis 4). Por ello, la presencia y articulación de los distintos modos, frente a la narración verbal y visual de un hecho mediático, con índole de violencia estatal, derivan en una construcción de la impresión sensible.

Además, los autores plantean un abordaje de la multimodalidad en términos de dimensiones y modos del significado. De esta suerte, se contemplan los modos (escritural, visual y audible) desde la composición del significado, a partir de la perspectiva representaciónal, social, organizativa, contextual e ideológica.

Nos enfocamos, entonces, en la integración y complementariedad de los modos semióticos existentes en la crónica estudiada y observamos la relación de predominancia que se da entre ellos. Por otra parte, el subtema que se deriva de este este estudio es la 
Giomar Daniela Gómez Camacho

Paula Karina Manrique Carvajal

lectura que se origina a partir del efecto emotivo, creado por la construcción y elección de los modos y los elementos presentes en estos.

Partimos de la hipótesis según la cual los recursos multimodales en la crónica "Dimar Torres: el crimen de un desmovilizado al que quisieron echarle tierra" convergen en la conducción de efectos pathémicos para manifestar lo oculto sobre el asesinato del desmovilizado, principalmente a través de la relación que se establece entre los modos y el efecto sensibilizador que estos contienen.

El análisis multimodal de un corpus cuyo contenido aborda problemáticas sociales del espectro público, implica la adopción de una mirada alternativa en los estudios multimodales, en relación con el análisis del discurso político. La razón de lo anterior es que las consideraciones de los efectos que tiene el diálogo entre modos se dirige hacia otra posibilidad de abordaje, como es el efecto pathémico que guarda las relaciones simétricas o no de los distintos potenciales semánticos.

\section{Metodología}

Se empleó el enfoque de la Gramática de la multimodalidad, desarrollado por Cope y Kalantzis (2009), dado que esta perspectiva permite abarcar gran parte de los elementos susceptibles de análisis en la crónica. De esta forma, La Gramática de la multimodalidad fungirá como el "marcado estructural y semántico" (99), de los modos tratados en el texto de análisis y su articulación.

En primera instancia, tuvo lugar una revisión somera de los materiales, que nos permitió identificar la preponderancia de uno u otro modo, y también, la forma en la que los elementos rastreados se pueden concatenar con lo propuesto por los distintos teóricos. Posteriormente, se estableció una categorización de las relaciones emergentes; dicha estructura tuvo la forma de una matriz categorial que vinculó los modos presentes en la crónica y su correspondencia con la revisión teórica que se ha realizado en paralelo. Particularmente, el foco se situó sobre el planteamiento de Cope y Kalantzis (2009), ya que la propuesta relaciona las dimensiones de significado, los modos de 
Efecto pathémico y veridicción en una crónica multimodal sobre la violencia de Estado en Colombia

significado y ejemplos particulares de los modos que integran el corpus. Por último, se realizó el análisis de los resultados obtenidos del estudio de la matriz categorial y se propuso una discusión.

\section{Resultados}

Seguidamente, se exponen de manera detallada cada una de las dimensiones abordadas en la matriz de datos recolectados, en relación con el análisis particular del corpus.

Dimensión representacional: los actores son, en primer lugar, José Guarnizo, autor de la crónica, quien realizó una investigación en torno al suceso mediático de la muerte de Dimar Torres. Igualmente, los personajes descritos en la crónica, que estuvieron en los momentos previos y reales de los hechos y cuyos testimonios son transcritos por Guarnizo. En esta sección, también se ubican las transcripciones de algunas entrevistas radiales recuperadas por Guarnizo para darle cuerpo a la crónica. Los agentes que forman parte de los recursos visuales y gestuales son quienes están retratados por la ilustradora Angélica María Penagos, a partir de los hechos y rasgos particulares referidos por el cronista. Respecto al audio, se registran en el corpus algunas notas de voz recopiladas y dispuestas por Guarnizo, de acuerdo con lo que va narrando.

Dimensión social: respecto a las relaciones de participante y observador indirecto, el vínculo que se establece entre los participantes (autor de la crónica y personajes) y el observador indirecto (el lector) es de apreciación informativa, con un corte que busca apelar a la emocionalidad. Por otra parte, se percibe que hay un plano focal de afecto, en la medida que se puede observar en la ilustración una madre abrazando a su hija y a Dimar abrazando a su esposa. Frente a las inferencias que se pueden establecer de las emociones retratadas, se destacan las acciones de los personajes en las ilustraciones, por ejemplo: algunos miembros de la comunidad están llorando alrededor del cadáver, o la mano de la esposa de Dimar Torres que está posada sobre su vientre embarazado.

En cuanto al modo de significado que implica el compromiso, puede decirse que la afinidad del cronista reside en el interés que tiene su investigación por develar un crimen 
Giomar Daniela Gómez Camacho

Paula Karina Manrique Carvajal

de Estado. Respecto a la gestualidad, es perceptible cómo, a partir de lo narrado por Guarnizo, la ilustradora construye, desde su subjetividad, las expresiones de los personajes.

Dimensión organizacional: el modo de comunicación del corpus responde al de la crónica o el reportaje en el que prima la narración y la descripción del antes, durante y después del asesinato de Dimar Torres. Lo anterior implica la presencia de un diálogo entre el autor de la crónica y las personas que fungen como testigos. Respecto a las imágenes fijas, se cuenta con cinco ilustraciones que corresponden a los apartados en los que el cronista estructura la historia. Como se mencionó anteriormente, la gestualidad implicada en las ilustraciones responde a las características particulares que el cronista menciona de los personajes. En relación con los ejemplos de audio, se evidencian los sentimientos naturales de los habitantes de Campo Alegre en el momento del hallazgo del cadáver. Además, la participación del inistro de defensa de ese periodo, Guillermo Botero, en la moción de censura, debate que tuvo lugar el 29 de octubre del año anterior.

Por otra parte, referente al medio de comunicación en el que es publicada la crónica, se observa que es a través del portal web de la Revista Semana, en un especial que es difundido con el fin de abordar este suceso mediático. La plataforma permite articular tres formas de representación: la primera, la narración y concatenación de los hechos, por parte del cronista, traducido en texto; la segunda, las ilustraciones que pretenden acompañar gráficamente al relato y, la tercera, los audios reales y algunos fragmentos de entrevistas. En el aspecto de presentación, se percibe el uso de una letra serifada y el acompañamiento del texto con un fondo gris con trama de puntos blancos, cinco ilustraciones digitales y cinco audios reales, con una entonación diferente en cada uno de ellos, que corresponde con el suceso que se narra en cada apartado y con los sujetos presentes en ellos.

En lo relativo a la cohesión, la estructura del escrito está conformada por cinco apartados, en los que el primero corresponde a la continuidad del título, con nueve párrafos e intercalados por los diálogos de los personajes. El segundo es llamado "El sueño perturbador" y consta de trece párrafos. El tercero es nombrado "Las raíces" y está distribuido en catorce párrafos. El cuarto es designado como "El ocultamiento" y 
Efecto pathémico y veridicción en una crónica multimodal sobre la violencia de Estado en Colombia

está dividido en diecisiete párrafos mediados por diálogo y, por último, se encuentra el quinto apartado denominado "Las mentiras" y está fragmentado por quince párrafos. Asimismo, las ilustraciones están distribuidas al final de cada uno de los episodios, enmarcadas e intercaladas con el texto. En la esquina inferior izquierda de las ilustraciones, salvo en el primero, los audios se ubican como preámbulo o ambientación de los episodios. Otros, sirven para mostrar detalladamente lo dicho por algunos personajes relacionados con el hecho.

Por último, respecto a la composición se encuentra que, en el plano de la lengua, el género corresponde a la crónica. La dimensión visual está enmarcada por la ilustración y, en la posición del audio, se presentan los audios reales y algunos fragmentos extraídos de entrevistas realizadas en emisoras radiales.

Dimensión contextual: en esta dimensión, se hablará únicamente de lo que atañe al Discurso. En este sentido, el empleo de figuras y de diminutivos permite esbozar una hipótesis respecto a la apuesta por la verdad que hace el periodista. Su uso del lenguaje denota compromiso genuino con su profesión, en el marco de un país en el que se suelen contar verdades a medias. Por su parte, en el campo de la ilustración, se tomaron en cuenta los gestos y posiciones de los personajes retratados. Así mismo, se considerócómo estas se vinculan a lo narrado por el cronista y los sucesos reales.

Aspecto ideológico: responde a las marcas de interés que ha delimitado el autor en el texto, en relación con la finalidad, la veracidad y lo que pretende resaltar. Por ello, se señalan elementos como la descripción de la vestimenta de los personajes que aparecen en la crónica (soldados, campesinos, familiares de Dimar Torres) en relación con los roles que tiene cada uno. También se menciona la intensidad registrada en los audios, los cuales refieren al momento real de los hechos y expone, de manera intensiva y emotiva, las reacciones de la comunidad al hallar el cadáver del desmovilizado. Adicionalmente, se presentan las construcciones lingüisticas que han sido utilizadas por el autor para manifestar la emotividad con la que pretende interpelar a la audiencia.

Continuando con el análisis, iniciaremos refiriéndonos a la relación de la teoría con la articulación de los modos. En segundo lugar, hablaremos de lo que implica la articulación modal con el efecto patémico que subyace al corpus. 
Giomar Daniela Gómez Camacho

Paula Karina Manrique Carvajal

El efecto que tiene el uso de la pantalla, en contraste con la página, mencionado por Kress, se refiere a la distribución del poder semiótico, dado el alcance que se pretende tener en la audiencia. Adicionalmente, podría decirse que la adopción de la pantalla permite la integración de los tres modos presentes en la crónica; acción que no podría darse en un medio como la página física, puesto que impide la inclusión del modo audible.

En lo que concierne a la preponderancia de un modo sobre otro, se evidencia que lo escrito tiene mayor alcance, en tanto que es el modo que dicta, de alguna manera, los contenidos de las ilustraciones y de los audios dan veracidad a lo que expone el modo escrito. Lo anterior se afirma puesto que, en los capítulos de la crónica, excepto en la portada, las ilustraciones y los audios, superpuesto a cada una de ellas, se presentan como un cierre de lo narrado por el cronista. En este sentido, se podría considerar que hay una pauta delimitada para que los lectores del texto comprendan la crónica como una verdad que es revelada.

Otro aspecto que surge del análisis tiene que ver con la forma en la que los modos están dispuestos. La relación audio-texto se da a partir de la búsqueda de evidencias que hace el autor; en esta medida, el texto se sirve del audio para tener una estructura sólida y bien fundada. En contraposición, la imagen apuntala lo dicho por el texto, es decir, se sirve de él para ser creada. Lo anterior se sustenta en los contenidos particulares de cada ilustración: el embarazo de Alexandra, los soldados cavando, los campesinos llorando, etc.

A partir de lo expuesto, es decir, la unión de los modos, se desprende un efecto totalizador del significado que quiere dar la crónica. Dicho efecto es resumido en lo señalado por Cope y Kalantzis como "sinestesia", debido a que cada modo crea un significado análogo a los otros. Esto se da porque el autor propone los modos como un complemento y no como unidades independientes. La presentación conjunta de todos los modos ocasiona una impresión sensible en el lector, ya que se observa desde distintas aristas dentro de las que es palpable recoger impresiones vívidas y con efecto realista del hecho narrado. 
Efecto pathémico y veridicción en una crónica multimodal sobre la violencia de Estado en Colombia

En vista de lo anterior, es preciso profundizar ahora en las reglas de producción retórica de la emoción propuestas por Plantin. La primera regla se refiere al hecho de estimular la emoción mediante la exhibición de objetos productores de ella; en el corpus se describe el hallazgo del cuerpo:

El cadáver de Dimar fue hallado boca abajo [...] tenía la espalda descubierta, la camisa estaba corrida hacia arriba, casi a la altura de los hombros. El jean, sin correa, lo tenía abajo de las rodillas. En la espalda y los glúteos se notaban varias escoriaciones (Guarnizo 2019).

La regla también se pone en funcionamiento en el siguiente fragmento: "A Dimar lo mataron con cuatro disparos calibre 5,56, todos provenientes de un fusil Galil" (Guarnizo 2019). Adicionalmente, en el momento del descubrimiento de la fosa en la que se pretendía ocultar el cuerpo de Torres, el cronista señala: "Hay palas enterradas y una olla con agua de panela. Parece una fosa con tierra fresca acabada de cavar. Dimar, sin embargo, no aparece. Una linterna apenas alcanza a captar una gorra militar y un chorro de sangre" (Ibid.).

La segunda regla comprende la representación de las situaciones-estímulos. En este caso particular, se ve cómo el cronista acude al protocolo de necropsia de Medicina Legal para mostrar a la audiencia la forma en la que se dio el asesinato: "Dimar recibió el primer disparo en la cara. En el dorso, un glúteo y la pierna izquierda se ubican los impactos de las otras tres balas" (Guarnizo 2019) Lo anterior permite ver que en el plano ideológico confluyen diferentes discursos, como el clínico y el jurídico. Además, es necesario mencionar que los modos restantes también siguen la lógica de esta regla. En la primera ilustración (Figura 1) se observa que Penagos acude al audio en el que los campesinos dejan registro de lo experimentado al encontrar el cadáver. 
Giomar Daniela Gómez Camacho

Paula Karina Manrique Carvajal

Figura 1:

Cuerpo de Dimar Torres

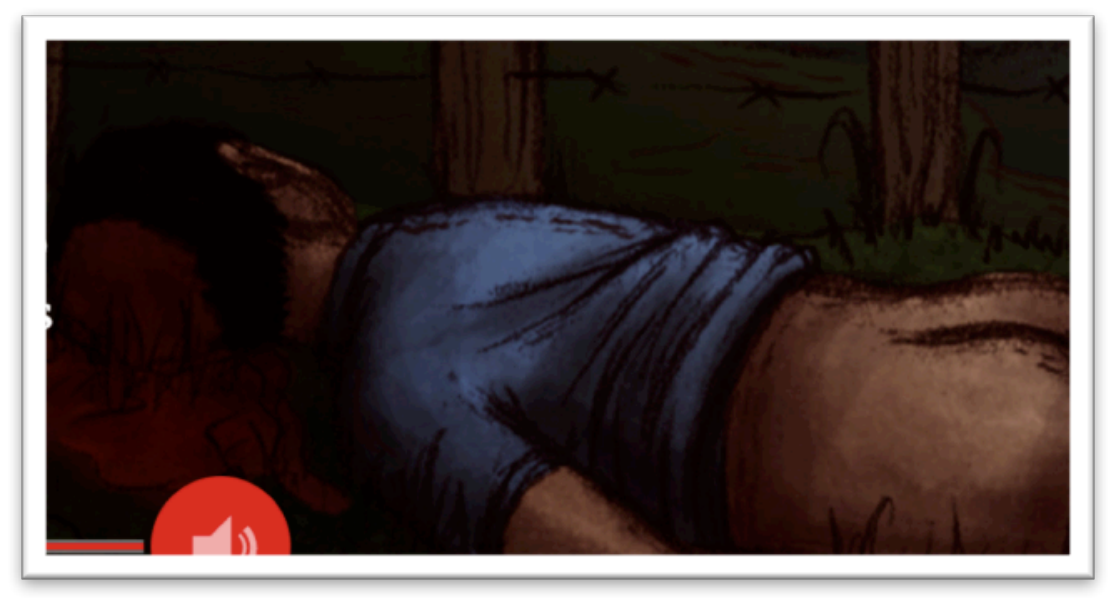

Fuente: Penagos (2019)

En tercer lugar, la siguiente regla alude a la relación mimética. Dicha relación implica la descripción y amplificación de los hechos o cosas emocionantes; además del perfilamiento, según Plantin, de los personajes en pares antagónicos, "personajes buenos" o "personajes malos". La amplificación y la descripción de los hechos emocionantes se ve materializada a través de los siguientes fragmentos que son una parte del audio transcrita por Guarnizo: "-Le quitaron hasta la ropa, iTriple hijueputas soldados! Mira eso, mira eso, dios mío. iParacos hijueputas!"; "La mujer, nerviosa y en shock, deja salir con dificultad una frase: - iQué pecao! Ay, dios mío" (2019).

Por otra parte, frente al perfilamiento de los pares antagónicos, señalaremos cómo se describe a Dimar Torres (personaje bueno) y al ministro de defensa (personaje malo). Al primero, se le describe como un personaje que gozaba de aceptación en el pueblo donde 
Efecto pathémico y veridicción en una crónica multimodal sobre la violencia de Estado en Colombia

empezó a hacer su vida después de la guerra: "Dimar, a sus 39 años, era un hombre muy querido en Campo Alegre" (Guarnizo 2019). En contraste, del segundo se exhiben algunas declaraciones que demuestran una postura evasiva y tendenciosa: "Si hubo un homicidio ha tenido que haber alguna motivación, a menos que haya sido un acto de esos de intemperancia o alguna cosa, vaya uno a saber por qué" (Id.). Adicionalmente, a esta regla se ajusta uno de los ejemplos expuestos en la tabla, pues, a través de la gestualidad de los personajes también se muestra su propensión a un carácter determinado. A Dimar se le ilustra con un rostro calmo; por el contrario, Botero es dibujado con rasgos propios de un energúmeno. Estas elecciones de la ilustradora se condicen con las tipificaciones clásicas del héroe y el villano.

La cuarta regla señala la presentación directa de las emociones, es decir, apuesta por las siguientes acciones: mostrar personas emocionadas, mostrarse emocionado y prestarle la voz a las personas emocionadas. Así las cosas, hemos escogido para la primera acción el contenido de la primera ilustración y los audios que aparecen en primer y segundo lugar, pues en ellos se registra el momento del hallazgo del cuerpo y el reclamo que la comunidad hace ante el ejército.

Figura 2: Los habitantes de Campo Alegre lloran a Dimar

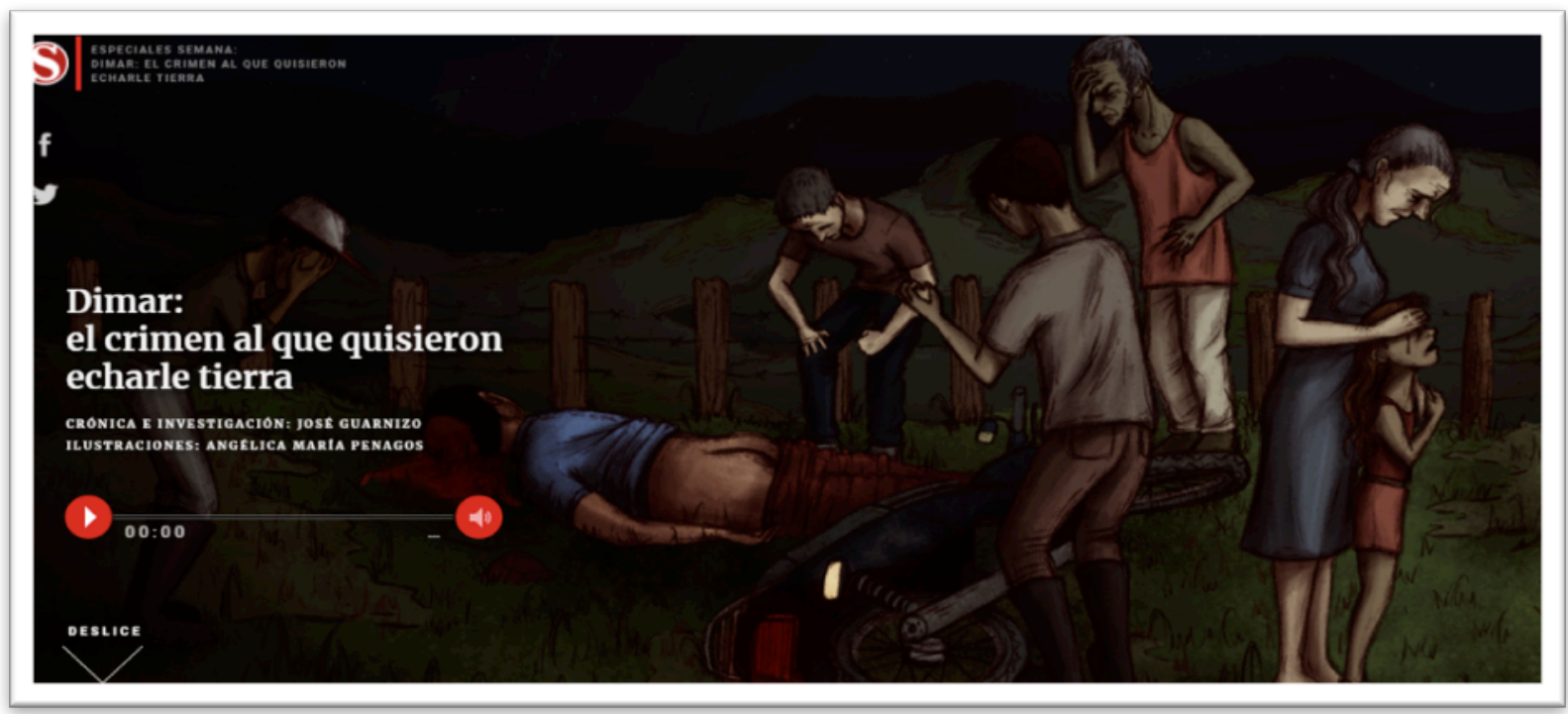

Fuente: Penagos (2019) 
Giomar Daniela Gómez Camacho

Paula Karina Manrique Carvajal

La segunda acción indica la necesidad que tiene el orador o quien profiere el discurso de mostrarse emocionado; sin embargo, dada la naturaleza del género, crónica, Guarnizo no se enuncia como un yo visible. No obstante, más adelante se ahondará en el uso de diminutivos o "formas afectivas de tratamiento", según Plantin, como una posible manifestación emotiva directa por parte del autor.

Por último, la tercera acción invita a prestarles la voz a las personas emocionadas. Como se ha mencionado en líneas anteriores, el contenido de los audios da muestra de las emociones que experimentó la comunidad de Campo Alegre en el momento de la confrontación y del hallazgo. Adicionalmente, el quinto audio, en el que se recogen varios fragmentos de entrevistas radiales en las que el ministro de defensa se manifiesta, se escucha cómo uno de los periodistas interpela a Botero así: "Los videos son escabrosos, ministro. Este exguerrillero recibe un tiro a contacto, muy cerca quiero decir, en la cabeza. iEl forcejeo dio para que el tiro le hubiera dado en la cabeza?" (Cit. en Guarnizo, audio 5, 7:34-7:47)

En relación con los principios de inferencia emocional propuestos por Plantin, realizamos un rastreo en el que se extrajeron los diferentes disparadores linguíisticos que dan cuenta de ello. El primero es denominado como Principio de relevancia emocional, y contiene tres subprincipios: proximidad, animacidad, y rango y número. A proximidad corresponden los deícticos, los términos de parentesco y las formas afectivas de tratamiento. Las evidencias halladas fueron las siguientes: Deícticos: "-iNosotros sabemos que lo tienen aquí! Porque al momento en que iba pasando, ustedes lo pararon" (Guarnizo 2019) Términos de parentesco: "así la recordaría Yaneth, hermana de Dimar" (Id.).; "Él se había demorado dos años levantando la pequeña estructura con ayuda de su suegro, don Dionergen Rodríguez Santiago" (Id.).

Formas afectivas de tratamiento: este punto fue desarrollado en el cuadro que diseñamos con base en la propuesta de Cope y Kalantzis. Traemos de nuevo dos ejemplos: "La casita era la alegría con la que se levantaba todos los días, la esperanza después de la guerra"; "Hasta allá había llegado en su motico Suzuki" (Guarnizo 2019). 
Efecto pathémico y veridicción en una crónica multimodal sobre la violencia de Estado en Colombia

El segundo subprincipio comprende la animacidad, es decir, los términos mediante los que aluden al peligro o a la conservación de la vida. Se plantea la disyuntiva vidamuerte. Con el fin de mostrar las evidencias de este subprincipio, la pesquisa lexicométrica de los lemas que denotan el conflicto de la disyuntiva mencionada anteriormente arroja la reiteración del lexema "disparo" (12 veces) y de otras recurrencias como "asesinato" (6 veces), "cadáver" (5 veces), "matar" (5 veces) y "cuerpo", como sinónimo de "cadáver" (9 veces).

El tercer subprincipio, referente a las tipificaciones de rango y número, aparece en los siguientes apartados: "en fila india los campesinos avanzaron por entre los matorrales, hasta que se encontraron de frente con el cabo segundo del Ejército, Daniel Eduardo Gómez Robledo, que les salió al paso en medio de la oscuridad"; "Esa es la misión del ejército" (Guarnizo 2019).

En cuanto a la evaluación emocional, esta abarca los ítems léxicos con connotaciones positivas y negativas. Se extraen las siguientes evidencias: negativas: "Con cada minuto que pasa aumenta la angustia"; "había mucha sangre" (Guarnizo 2019). Positivas: "Se sentía enamorada de Dimar y quería conformar con él un hogar"; "Le habría dicho, con una risa nerviosa atravesándole la cara, que las dos rayitas que habían aparecido en la prueba de embarazo no eran una equivocación" (Id.).

Por su parte, la intensidad de presentación implica el uso de detalles o recursos literarios al interior del discurso. Se extrajeron los siguientes fragmentos: "En la noche los gatos son pardos, suelen decir en el campo. Y las sombras aquí son el mayor obstáculo"; "En el Catatumbo las heridas del conflicto quedaron intactas"; "La casita era la alegría con la que se levantaba todos los días, la esperanza después de la guerra"; "Era la esperanza de un pedacito de paz en el Catatumbo"; "Aquellos episodios de los falsos positivos del pasado llegaron a Campo Alegre como fantasmas la noche en que se supo que Dimar había sido abordado por un cabo del Ejército para hacer una requisa"; "La noche cayó como una amenaza y un mal presagio sobre Carrizal"; "Se incorporó y abrazó a su hermana Yulianis como si fuera un niño que tiene miedo de seguir durmiendo"; "Las linternas de los campesinos alumbraron la materialización de la 
Giomar Daniela Gómez Camacho

Paula Karina Manrique Carvajal

tragedia misma"; "Y a la tierra, poblada ahora de recuerdos frescos, seguramente le nacerá la maleza" (Guarnizo 2019).

Por último, Plantin expone el Principio de contenido emocional en el que recoge los términos que manifiestan una descripción de la emoción, clasificados en sustantivos, adjetivos y verbos. Extrajimos los siguientes ejemplos, de los cuales se establece una categorización entre los términos que aluden a las personas y los que refieren al crimen. Personas: "Es en ese instante en que aparece por primera vez en las imágenes, el cabo Gómez Robledo, que aparece perturbado por la situación"; "La comunidad, se ve en las imágenes, insiste, se impacienta, se exaspera"; "Con cada minuto que pasa aumenta la angustia"; "Otros de los campesinos simplemente se quedan callados, perplejos. Los gritos y el llanto se mezclan"; "Por eso la tensión, la desconfianza, la zozobra"; "Llevaba una gorra negra, la mirada perdida, el semblante abatido. El viejo se veía opacado"; "Los campesinos comenzaron a arremolinarse alrededor de Dimar, estaban estupefactos. Hubo lágrimas, gritos, indignación, rabia. Es difícil describirlo en palabras". (Guarnizo 2019) Escena del crimen: "había mucha sangre"; "Según el protocolo de necropsia..." (Id.).

A tenor de lo expuesto, es posible afirmar que el análisis multimodal deriva en la determinación del modo escritural como modo preponderante en el texto. Dicha preponderancia estriba en que los otros dos modos: visual o ilustrativo y audible apuntalan la emoción y la descripción que Guarnizo pretende hacer del hecho noticioso.

De esta forma, observamos que los modos, a la luz de la propuesta de Plantin, integran reglas y principios que propenden hacia la construcción del efecto pathémico. De ahí que la hipótesis de nuestra investigación, que especula sobre el posible efecto sensibilizador presente en la forma en la que Guarnizo expone los hechos, se cumpla de manera uniforme en el corpus.

\section{Conclusiones}


Efecto pathémico y veridicción en una crónica multimodal sobre la violencia de Estado en Colombia

Propusimos el análisis de la crónica multimodal "Dimar Torres: el crimen de un desmovilizado al que quisieron echarle tierra", a partir de un modelo de conjunción de rasgos y modos generadores de sentido (Cope y Kalantzis 2010). El hallazgo principal concierne a la forma en la que los textos contemporáneos, atravesados en su mayoría por la multimodalidad, se configuran y generan un sentido de "lo verdadero", "lo revelado" o "lo no contado" a partir de lo retórico e ideológico.

Los modos conjugados dan muestra de la caracterización de los actores (representacional); también, exhiben los roles asociados de cada uno de ellos (social). A partir de la disposición del corpus también fue posible determinar su estructura interna (organizacional). En cuanto a las elecciones discursivas del autor, fue posible determinar los aspectos contextuales que rodearon a la producción narrativa (contexto). Por último, la dimensión ideológica del significado tendió a la heterogeneización de voces y fuentes, así como al uso de algunos adjetivos que podrían reforzar la idea determinada en nuestra hipótesis. En esta misma línea, es pertinente mencionar que, a pesar de que existe una marcada preponderancia del modo escrito, los otros dos modos enfatizan de forma armónica el efecto buscado. El concepto de sinestesia en sí mismo se ajusta en razón de que implica la sinergia de distintos planos. Esto es aplicable a la forma en que se engranan los tres modos para generar un efecto uniforme.

Respecto al componente retórico-discursivo, es posible decir que las reglas de producción retórica de la emoción ayudan a construir los efectos buscados a partir del estímulo, la representación de la situación, la descripción y amplificación de hechos emocionantes y la presentación directa de las emociones. Asimismo, en el corpus es apreciable la forma en la que se combinan las diferentes formaciones linguísticas que funcionan como componentes de la conducción emocional. Tales principios son conjuntos que clasifican las elecciones particulares que hace el emisor del discurso y que ayudan a asentar el componente emocional o pathémico que anida en la construcción de un discurso con efecto de verdad, a partir de la aparición de diversos agentes que revisten "la versión verdadera" de un hecho que fue negado y, posteriormente, mitigado a nivel nacional, por personajes que detentan una posición de poder. 
Giomar Daniela Gómez Camacho

Paula Karina Manrique Carvajal

Las tres propuestas teóricas convergen en el punto en el que Guarnizo, a través de la publicación de su trabajo en una pantalla, redistribuye el poder semiótico, puesto que las publicaciones circulan de forma más libre en la web. Así, el alcance se amplía. Más difusión implica más lectores que pueden sentirse interpelados por la articulación del texto. El diálogo entre lo que se narra, lo que escucha y lo que se ve, puede derivar en que el auditorio al tener una visión más prismática del hecho, tienda a sensibilizarse y a eliminar, de forma progresiva, los prejuicios que pueden ser alimentados por una burbuja semiótica.

Finalmente, un posible contraargumento podría oponerse a la posibilidad de estimar la intención de quien enuncia; no obstante, en este análisis se expone un camino de lectura que deja abierta la posibilidad de proponer otra ruta que indague a través de otras propuestas teóricas. Para el alcance acotado de este artículo, dejamos indicado el problema de la semiotización multimodal de la verdad en contextos de violencia política en los cuales la apelación a las emociones parece ser más efectiva que la contradicción argumentativa monomodal de las versiones oficiales y hegemónicas acerca de los crímenes del Estado. Por último, con el fin de profundizar en el efecto de verdad que pueden proveer los textos multimodales en el marco de la violencia estatal, podrían analizarse producciones nacionales como el documental de Jesús Abad Colorado El testigo: Caín y Abel (2018), además de otras crónicas de José Guarnizo como: Ariolfo: el campesino al que mató el ejército y por el que nadie responde (2020) y El ejército no solo mató a Salvador: lo graduó de guerrillero sin serlo (2020).

\section{Referencias}

Aristóteles. Retórica. Madrid: Gredos, 1994.

Cope, Bill. \& Kalantzis, Mary. "Gramática de la multimodalidad”. (C. Pasadas Ureña, trad.). Boletín de la Asociación Andaluza de Bibliotecarios (2010): 93-152.

El testigo. Jesús Abad Colorado. Dir. Kate Horne, 2000. Documental. 
Efecto pathémico y veridicción en una crónica multimodal sobre la violencia de Estado en Colombia

Fernández, Raquel. "Multimodalidad e hipertextualidad en La ciudad ausente de Ricardo Piglia: de la novela gráfica a La ópera de Gandini”. Universidad de Almería (s.f.) https://dialnet.unirioja.es/servlet/articulo?codigo $=5327412$

Ferreira, Mariana. "La novela gráfica y pasiones aristotélicas em Rugas, de Paco Rocca" Universidad de Franca, 2020.

Foucault, Michel. Estética, Ética y Hermenéutica. Obras esenciales. Volumen 3. Barcelona: Paidós, 1999.

Guarnizo, José. "Dimar Torres: el crimen al que quisieron echarle tierra". Especiales

Revista Semana. (2019). https://especiales.semana.com/el-asesinato-de-dimartorres/index.html

Guarnizo, José. "Ariolfo: el campesino al que mató el ejército y por el que nadie responde". Vorágine: Historias. (2020). https://voragine.co/ariolfo-el-campesino-quemato-el-ejercito-y-por-el-que-nadie-responde/

Guarnizo, José. "El ejército no solo mató a Salvador: lo graduó de guerrillero...sin serlo". Vorágine: Historias. (2020). https://voragine.co/el-ejercito-no-solo-mato-asalvador-lo-graduo-de-guerrillerosin-serlo/ Guijarro, Rodrigo. "La multimodalidad en la narrativa española". Universidad Complutense de Madrid. (s.f.). http://revistas.uned.es/index.php/signa/article/view/25093

Kress, Gunther. El alfabetismo en la era de los nuevos medios de comunicación. (J. Pomares, trad.) Málaga: Editorial Aljibe, 2005.

Plantin, Christian. Las buenas razones de las emociones. (Ghelfi, E., trad.) Buenos Aires: Universidad Nacional de Moreno, 2014. 